\title{
Using a Community Farmers' Market to Engage Students From an Alternative School
}

\author{
Eric Hogan \\ Georgia Southern University \\ Sean Forbes \\ Auburn University
}

A university-school-community partnership was created through an agricultural initiative. As the program progressed, four high school interns from an alternative school were hired. We explored their lived experiences related to academic social capital when working in a Community Farmers' Market. We utilized ethnographic means when working with the interns. Data collection involved observation, conversations, and field notes. These were then taken to create audio reflections to provide depth to the interactions. Then we transcribed the audio reflections and looked for themes related to academic social capital. Findings included those things that facilitated and constrained the students' academic social capital. We also discuss how we experienced personal growth and reflected on how hiring the interns changed the program for the better.

Keywords: ethnography, alternative education, Community Farmers' Market

\section{INTRODUCTION}

An emerging role for universities is one of active neighborhood involvement, in which they are engaged in projects with local communities fostering human capital (Breznitz \& Feldman, 2012). This is especially pertinent for Colleges of Education whose mission involves serving P-12 and college students alike. Colleges of Education, then, are encouraged to create university-school-community partnerships.

Bridger and Alter (2006) suggested that "Universities possess the intellectual resources and capabilities to help realize this vision [development of community]. But university potential can be realized only if faculty embrace their role as citizen and expert simultaneously. This orientation requires that individual faculty see their work as contributing to the development of community by consciously focusing on civic renewal while also providing expert advice and assistance. To accomplish these often-competing objectives, faculty must strive to develop a complementary relationship between scholarly achievement and the public good."

\section{COMMUNITY FARMERS' MARKETS}

Community Farmers' Markets (CFMs) can represent community centerpieces and central gathering spaces (Feagan \& Morris, 2009). Since the United States Department of Agriculture (USDA) began 
recording the number of farmers markets in 1994, the prevalence has increased from 1755 to 8761 in 2019 (U.S.D.A. Agricultural Marketing Service, 2021). Partnerships between academia and organizations supporting farmers markets have stimulated the development of new tools to allow markets to engage in "citizen science" to track and communicate the impact of their markets on local communities (Warsaw, Archambault, He, \& Miller, 2021).

Farmers' markets connect citizens as neighbors, consumers, producers, and community groups to the food system, providing opportunities for social interaction, commerce, entertainment, and information transfer (Kirwan, 2004). Russomanno \& Jabson Tree (2021) reviewed literature and found that a sense of community could be an important factor in determining who shops at farmers markets and the frequency with which they visit. Brown and Miller (2008) reviewed the impacts of farmers markets on local communities and found that farmers' markets generate significant economic benefits for both local economies and farmers.

\section{OP GROWS (PSEUDONYM)}

Wanting to promote outreach, Op Grows was created to bridge university and community. The organization did so by engaging P-12 students and community members alike by building and maintaining school and community gardens. Eventually Op Grows launched a Community Farmers' Market. Op Grows consists of higher education personal in various Colleges from a University, most notably from a College of Education. The researchers in this study, henceforth referred to as 'we', are both members of Op Grows with backgrounds in Educational Psychology. Educational Psychology as a discipline looks at ways to engage individuals to impact their learning and motivation. For this study, we specifically focused on students.

\section{Interns Hired to Work for Op Grows}

As Op Grows expanded, there was a need to increase the number of personal. Like Farmers' Markets, P-12 schools are also community centerpieces. Recognizing that, Op Grows hired high school interns. This would further strengthen connections between parties, whereby higher education personal, students, and community members could come together to share resources, thus creating a university-school-community partnership.

Each high school intern in this study attended an alternative school, the Carson Learning Center (pseudonym), for falling behind academically, on the cusp of dropping out, and had been in trouble both in and outside of school. Caroleo (2014) mentioned alternative education is used as progressive education, last chance education, and remedial instruction. Bjerk (2012) mentioned that those who drop out for reasons including expulsion, poor grades, moving, and not liking school do substantially worse than otherwise similar high school completers in terms of success in the labor market and getting in more trouble with law enforcement.

Purposeful sampling was used to recruit the high school students to be part of the internship program. We asked the principal of the school to identify a list of students that met the needed minimum requirements for participation: 1) the student had considered dropping out, 2) the student had been in trouble either in or out of school, and 3) the student would potentially benefit from working with a community organization.

The principal identified four young men who met all these requirements. These students were then asked if they wanted to enroll in a Agricultural and Food Systems course taught by the researchers at the same school. Each student agreed to enroll giving them more opportunity to grow plants and create projects such as birdhouses while in school. The principal did not look to recruit young women for the internship because most of them attended the alternative school as part of the new or expectant mother program and were not necessarily falling behind academically or at the school for disciplinary reasons. By the time the CFM started, however, only three of the original interns had maintained their employment. The three interns were Danny, Malik, and Stanton (pseudonyms).

At the time of the study, Danny was a rising senior at the alternative school while working in the CFM. Danny was sent to the Carson Learning Center for damaging school grounds years prior. Malik was also a 
rising senior, though he attended school infrequently, so his credit hours were more in jeopardy. Malik was sent to the alternative school when someone threatened to attack him, and he sought protection. Stanton was a rising junior and was sent to the alternative school for stealing a person's phone. The Op Grows internship was the first job for each of these individuals. Each intern suggested that school was not a pleasant experience and that they believed being in school did not offer beneficial resources. In that, the three students believed they had less academic social capital.

\section{ACADEMIC SOCIAL CAPITAL}

Social capital broadly is described as an investment in social relations by individuals through which they gain access to embedded resources to enhance expected returns of instrumental or expressive actions (Lin, 2001, p. 19). Bourdieu (1986) suggested that social capital is 1) cumulative, 2) possesses the capacity to produce profits or benefits in the social world, 3) is convertible into tangible resources and other forms of capital, and 4) possesses the capacity to reproduce itself in identical or in an extended form.

Expanding on social capital, Hogan, Forbes, \& Andrzejewski (2021) defined academic social capital as "The resources obtained from multiple social contexts that influence academic attainment, achievement, and success. Further academic social capital involves those social investments within and out of school that help a student to succeed and look for future opportunities including, but not limited to, having access to tutoring, knowing people with higher levels of schooling that can offer advice on current or future directions, and knowing people who have information on what a student is learning."

\section{INTERNS’ ROLES DURING THE FARMERS’ MARKET}

Initially when the interns were hired, they were tasked with managing the school and community gardens. This included planting, harvesting, and to help build raised beds and a greenhouse. As the program, moved forward, the Community Farmers' Market was created. The interns were tasked with various jobs at the CFM. The interns would help the vendors set up their booths, setting up canopies, unloading produce, etc. Another role involved directing traffic and helping community members carry things such as watermelon or peaches back to their cars after purchase. Most notably, the interns were able to sell products they had created while working for Op Grows or during the Agricultural and Food Systems class. The intern kept any money made from their products.

\section{PURPOSE AND RESEARCH QUESTION}

The purpose of this article is to explore the lived experiences of interns hired to work for an agricultural internship during a Community Farmers' Market. Ethnographic means were used to better understand the interns' academic social capital. The research question for this study is: What are the lived experiences that facilitated or constrained academic social capital for high school interns working in a Community Farmers' Market?

\section{DATA COLLECTION}

Within qualitative methods, data collection is typically broken up into four strategies: observations (ranging from nonparticipant to participant), interviews (ranging from close-ended to open-ended), documents (ranging from private to public), and audiovisual materials (including materials such as

photographs, compact discs, and videotapes) (Creswell, 2013, pp 159). For this study, we utilized observations, conversations, field notes, and audio reflections to explore the lived experiences of the interns.

\section{Observations, Conversations, and Field Notes}

Observations and conversations with the interns were recorded in our own field notebook each time we interacted with the interns. In the field notebook, we highlighted events and conversations that occurred 
throughout the day specifically related to the interns' academics. The field notes were used as primers for audio recordings.

\section{Audio Recordings}

These audio recordings were recorded after the conclusion of the interaction with the interns to make sure our shorthand notes were not forgotten. The audio recordings were expansions of the field notes. In these audio recordings, we would say the date, the length of the workday, who worked/participated, various things that occurred during the day such as how well the interns worked, the revisiting of conversations, personal reflection on the daily tasks, and continual reflections from past recordings.

"The full meaning of reflexivity in ethnography refers to the ineluctable fact that the ethnographer is thoroughly implicated in the phenomena that he or she documents, that there can be no disengaged observation of a social scene that exists in a "state of nature" independent of the observer's presence, that interview accounts are co-constructed with informants, that ethnographic texts have their own conventions of representation. In other words, "the ethnography" is a product of the interaction between the ethnographer and a social world, and the ethnographer's interpretation of phenomena is always something that is crafted through an ethnographic imagination" (Atkinson, 2006).

\section{DATA ANALYSIS}

Every audio recording that we produced were transcribed. To organize these data, we organized all transcriptions from both researchers in chronological order. We then read each transcription individually to understand the interaction with the interns from multiple perspectives. Coding the transcriptions was guided by a priori notions related to academics, specifically the facilitation and constraint of their academic social capital. Another a priori code was our personal growth while working with the interns. Our final a priori code involved looking at how the partnership between university, school, and community changed. We tagged this code as Op Grows Programming.

We further wanted to organize the data. We took notes on the a priori notions to determine themes from each code. DeSantis and Ugarriza (2000) suggested, themes are abstract entities that bring meaning and identity to a recurrent [patterned] experience and its variant manifestations, thus themes capture and unify the nature or basis of the experience into a meaningful whole. To find themes and to establish transparency and trustworthiness, we compared our notes for intercoder agreement. Intercoder agreement allows coders to seek agreement on codes, themes, or both (Armstrong et al., 1997; Creswell, 2013 pp. 253-254). After a third read of the transcriptions, we agreed on numerous themes that fit under each a priori code. These will be discussed in the findings.

\section{FINDINGS}

Again, the purpose of this article was to explore the lived experiences of interns working in Community Farmers' Market. A prioi codes were: 1) Things that Facilitated Academic Social Capital, 2) Things that Constrained Social Capital, 3) Personal Growth, and 4) Op Grows Programming.

When documenting the findings, we share stories from our time working with the interns during the Community Farmers' Market. We use a narrative ethnography approach to position the stories. In a narrative ethnography, the world is re-presented as perceived by a situated narrator, who is also present as a character in the story that reveals their own personality enabling the reader to identify the consciousness which has selected and shaped the experiences within the text (Tedlock, 1991). We organize the story with the a priori codes and dive deeper within the various themes that were found. We use thick, rich description to build credibility. A thick description involves describing a phenomenon in sufficient detail so one can begin to evaluate the extent to which the conclusions drawn are transferable to other times, settings, situations, and people (Lincoln \& Guba, 1985). 


\section{Things That Facilitated Academic Social Capital}

Interacting With School Personal

Academic social capital involves those resources obtained from multiple social contexts that influence academic attainment, achievement, and success (Hogan, Forbes, \& Andrezejewski, 2021). The interns had the opportunity to sell products they made within the class and when working with Op Grows. Allowing the students to make these projects serendipitously created better relationships between administrators/teachers and the interns. Upon hearing that the interns were selling products, multiple administrators and teachers came to the Community Farmers' Market. The Principal of the school went out of his way to purchase something from Danny, Malik, and Stanton. This supported Bourdieu (1986) notion of social capital in that it something was created into something tangible and created a profit. Multiple teachers commended the interns' efforts on learning how to design and sell a product. The simple acts of encouragement helped strengthen the interns' social networks where academic resources could be fostered. Coleman (1988) and Burt (2000) suggested structure of networks facilitate social capital.

\section{Talking About Resources}

Another way academic social capital was facilitated was how long the interns interacted with both researchers. Again, we have a background in Educational Psychology. In that, we both have had to navigate various academic spheres. Most notably, we have experience in higher education. Stanton utilized our knowledge of higher education to begin the application process to college. Stanton working for Op Grows became a jumping off point for what he would do post-graduation. In talking to Danny and Malik, both indicated limited desire to attend school beyond high school, however both did mention how they finally saw people caring about their academic success. Both committed to graduating also.

Things That Constrained Academic Social Capital. Within qualitative research, one aspect to further build credibility for the researchers is the use of disconfirming evidence. Disconfirming evidence is the process where investigators first establish the preliminary themes or categories in a study and then search through the data for evidence that is consistent with or disconfirms these themes (Creswell \& Miller, 2000; Miles \& Huberman, 1994). We are imperfect; thus, the programs we work with also have aspects that might not work the way they intended. We now turn our focus on aspects that constrained academic social capital to challenge our positive perceptions of the program.

\section{Working During the Summer}

The first thing that constrained academic social capital was when the Community Farmers' Market took place. This occurred during the summer when the interns were not attending school. Slates, Alexander, Entwisle, and Olson (2012) indicated that social capital resources could be impacted from the summer slide or lull when students are not in school. Despite the administrators and teachers coming to the garden, the interns were not engaging with school personal on a weekly basis. This would be important given how each intern committed to graduating but were not having to think about this goal regularly. Being outside of school allowed the interns to defer these commitments.

\section{Not Showing Up to Work}

Another factor that constrained academic social capital was not attending work when scheduled. As mentioned previously, Malik attended school infrequently. There were also times where Malik would not be responsive to phone calls or texts to remind him of the days he was supposed to work. When he did not show up to work at the CFM, there would be less opportunities to sell his products especially to those administrators and teachers that wanted to support him.

However, we do want to indicate that Malik not showing up was, in part, related to various personal issues he was facing at the time. In that, we tried to be as flexible as we could with his schedule. Not being at work, we did feel that this constrained his academic social capital, but we did try to grasp how many things can impact a person's life that are beyond someone's control. Trying to understand others holistically leads to our next theme of our personal growth. 
Personal Growth. As we aim to be better practitioners, we must have personal reflection. As Hogan (2017) mentioned, "Reflection from an individual standpoint allows for clarity in potential biases and one's strengths or weaknesses. Reflection in a communal sense creates a partnership where dialogue can occur. Both from the individual and communal sense, reflection better equips what has been done, what can be done, and what is currently happening." Or as Addams (1902) said, "As an ethical system, it placed on each person 'a moral obligation' to choose experiences of 'mixing on the thronged and common road' where we can 'least see the size of one another's burdens."

\section{Language Use}

During the thematic coding, something evident in our personal reflections was how our language had shifted to be more inclusive. Despite working with the interns for a few months prior to the Community Farmers' Market, we still used terms that were dismissive. A term used often enough was "at-risk". We would indicate to colleagues that we had hired "at-risk" youth. Historically, the term "at risk" as it applies to youth appears to have been borrowed from the medical study of the causes and effects of diseases and the identification of risk factors that make humans susceptible to diseases (Rea \& Zinskie, 2015).

However, as we reflected, we soon realized the interns never referred to themselves as such. Our higher education background had given us an "ivory tower" approach to school and community involvement. Rather than serving students and community, we were misrepresenting and perpetuating stereotypes. We wanted to do better so we became more cognizant of our language use. Though, we both acknowledge more growth is always needed. A new goal, yet important goal of Op Grows was to value each of its members.

Op Grows Programming. To start this article, we mentioned how an emerging role for universities is one of active neighborhood involvement, in which they are engaged in projects with local communities fostering human capital (Breznitz \& Feldman, 2012). Given our backgrounds in Educational Psychology and representing higher education, we sought to create partnerships between university, school, and community. As we are reflecting, we want to conclude our findings sections by indicating things that allowed these partnerships to be built and maintained.

\section{Donating to a Local Community Market}

An aspect that advanced the mission of Op Grows was always to donate produce to a local community market. After building relationships with some of the farmers that sold produce at the CFM, a few agreed to donate in the name of Op Grows. We could not have accomplished this caravan without the interns where they helped unload produce at the community market. Upon seeing the hard work put in by the interns, the person in charge of the community market allowed the interns to work extra hours on site. This was especially important when work weeks at the various gardens were slow. By donating produce, a web of connections was created that gave Op Grows encouragement for future expansion.

\section{More Support From Higher Education Administration}

The program grew since the start of the internship. None of this would have been possible without the support of various administrators at the university. They provided financial backing that allowed us to start the program and hire the interns. Much like the high school administrators, there was support by our administrators when they came out and met the interns, saw the growth of the program, etc. We wanted to highlight this theme to encourage higher education administration to gamble these kinds of programs. Without taking a chance, Op Grows would not be Op Grows today and thus would not have as much impact building localism.

\section{IMPLICATIONS}

A university-school-community partnership was established with a Community Farmers' Market. It was our intention to incorporate students into a community program where everybody gains something. This research adds to the literature of how higher education personal can build partnerships with various entities. It further gives appreciation that we as practitioners need to be reflective in our language and action. 
Noteworthy to consider is how programs might have good intentions but potentially constrain opportunities. This was especially the reason why we needed to share disconfirming evidence (Creswell \& Miller, 2000; Miles \& Huberman, 1994).

We used qualitative means to understand the lived experiences of high school interns. This study should be considered in the context in which it took place. The experiences cannot be replicated, but hopefully others were able to see the importance of creating partnerships. Incorporating those from a school might lend itself to universities becoming better community advocates.

\section{LIMITATIONS}

Despite the implications of this study, there were still limitations. Most notably, we did not member check nor use different data triangulation techniques. Member checking involves taking the data and interpretations back to the participants in the study so that they can confirm the credibility of the information and narrative account (Creswell \& Miller, 2000). By not member checking, we limited ourselves in how we could portray the interns. Data triangulation is a validity procedure where researchers search for convergence among multiple and different sources of information to form themes or categories in a study (Creswell \& Miller, 2000). Our source of data mainly came from observations, conversation, and field notes, which were eventually turned into audio recordings and transcriptions. However, we did not collect other forms of data that could give us a more holistic picture of academic social capital as the Community Farmers' Market was taking place. One thing that would have been helpful would have been to utilize social networks (Borgatti, Everett, \& Johnson, 2018; Carolan, 2014) to study how academic resources spread through a network.

\section{FUTURE RESEARCH}

Considering the limitations, further research is needed. First, more research is needed to triangulate data and member check. As mentioned, social networks could be used to better understand how academic social resources spread through a network. It would also be imperative to incorporate the participants into the study. In that, we could schedule interviews with participants, especially as new interns are hired, so their story is told exactly how they want it to be told. Incorporating them also could mean as researchers and having them reflect on their own academic social capital.

Additionally, research is needed on the impacts of Community Farmers' Markets as they relate to schools and/or students. Other areas that would be worth exploring involve how schools combat local food insecurity, how schools teach students about food systems, or how produce grown at school gardens can act as a catalyst for social change.

Next, more research is needed to better understand how universities are meeting their vision to develop community. More research is needed on how universities work within a community to better understand how resources can be shared to advance partnerships. Finally, more research is needed on how higher education personal listen to community members.

\section{CONCLUSIONS}

Our hope with this article was that readers could better understand how an agricultural program, Op Grows, built university-school-community partnerships. Higher education personal facilitated these partnerships through a Community Farmers' Market. Students were recruited from an alternative school to help manage this weekly event. During the summer, we got to work with the interns and explore their lived experiences. Specifically, we looked to understand how the Community Farmers' Market facilitated or constrained academic social capital. We found that by being able to sell products allowed faculty and staff from the school to support their work. We also found that academic social capital could be facilitated from interactions with those working in higher education. Though, we found that Community Farmers' Market 
taking place over the summer as well as a lack of attendance at work might constrain academic social capital. We also were challenged in our language use and saw Op Grows make progress as a program.

As practitioners, we must continue to reflect so university-school-community partnerships can be created and maintained. Universities can provide resources to communities and schools. We did so through a Community Farmer's Market where we hired high school interns. However, there are a multitude of ways to engage. University potential can be realized only if faculty embrace their role as citizen and expert simultaneously (Bridger \& Alter, 2006).

\section{REFERENCES}

Addams, J. (1902). Democracy and Social Ethics. New York: McMillan.

Armstrong, D., Gosling, A., Wesiman, J., \& Mareau, T. (1997). The place of interrater reliability in qualitative research: An empirical study. Sociology, 31, 597-606.

Atkinson, P. (2006). Rescuing Autoethnography. Journal of Contemporary Ethnography, 35(4), 400404.

Burt, R. (2000). Structural holes verses network closure as social capital. In N. Lin, K. Cook, \& R. Burt, Social Capital: Theory and Research. Chicago: Aldine Transaction.

Bjerk, D. (2012). Reexamining the impact of dropping out on criminal and labor outcomes in early adulthood. Economic of Education Review, 31(1), 110-122.

Borgatti, S.P., Everett, M.G., \& Johnson, J.C. (2018). Analyzing social networks (2nd Ed.). Sage Publications UK.

Bourdieu, P. (1986). The forms of capital. In J. Richardson (Ed.), Handbook of Theory and Research for the Sociology of Education (pp. 241-258). New York, Greenwood.

Breznitz, S., \& Feldman, M. (2012). The engaged university. The Journal of Technology Transfer, 37(2), $139-157$.

Bridger, J., \& Alter, T. (2006). The engaged university, community development, and public scholarship. Journal of Higher Education Outreach and Engagement, 11(1), 163-178.

Brown, C., \& Miller, S. (2008). The impacts of local markets: A review of research on farmers markets and community supported agriculture (csa). American Journal of Agricultural Economics, 90(5), $1298-1302$.

Carolan, B. (2014). Social network analysis and education: Theory, methods and applications. Sage Publications, Inc.

Caroleo, M. (2014). An examination of the risks and benefits of alternative education. Relational Child \& Youth Care Practice, 27(1), 35-46.

Coleman, J. (1988). Social capital in the creation of human capital. The American Journal of Sociology, 94, S95-S120.

Creswell, J.W. (2013). Qualitative inquiry \& research design: Choosing among five approaches. Thousand Oaks, CA: Sage Publications.

Creswell, J.W., \& Miller, D. (2000). Determining validity in qualitative research. Theory Into Practice, $39(3), 124-130$.

DeSantis, L., \& Ugarriza, D.N. (2000). The concept of theme as used in qualitative nursing research. Western Journal of Nursing Research, 22(3), 351-372.

Feagan, R.B., \& Morris, D. (2009). Consumer quest for embeddedness: A case study of the Brantford farmers' market. International Journal of Consumer Studies, 33(3), 235-243.

Hogan, E. (2017). Pragmatic social justice: A conceptual framework for practitioners. Essays in the Philosophy of Humanism, 25(1), 43-52.

Hogan, E., Forbes, S., \& Andrzejewski C. (2021). Academic social capital of students from an alternative school: An ego network perspective. International Studies in Sociology of Education.

Kirwan, J. (2004). Alternative strategies in the UK agro-food system: Interrogating the alterity of farmers' markets. Soc. Rural, 44(4), 395-415.

Lin, N. (2001). Social capital: A theory of social structure and action. Cambridge University Press. 
Lincoln, Y., \& Guba, E. (1985). Naturalistic Inquiry. Newbury Park, CA: Sage Publications, Inc.

Miles, M.B., \& Huberman, A.M. (1994). Qualitative data analysis: An expanded sourcebook (2nd ed.). Newbury Park, CA: Sage.

Rea, D., \& Zinskie, C. (2015). Making the American dream a reality for all youth: Introduction to the first issue of the national youth-at-risk journal. National Youth At-Risk Journal, 1(1), 1-12.

Russomanno, J., \& Jabson Tree, J.M. (2021). Assessing sense of community at farmers markets: A systematic review. Journal of Agriculture, Food Systems, and Community Development, 10(2), 489-506.

Slates, S., Alexander, K., Entwisle, D., \& Olson, L. (2012). Counteracting summer slide: Social capital resources within socioeconomically disadvantaged families. Journal of Education for Students Placed at Risk, 17(3), 165-185.

Tedlock, B. (1991). From participant observation to the observation of participation: The emergence of narrative ethnography. Journal of Anthropological Research, 47(1), 69-94.

U.S.D.A. Agricultural Marketing Service. (2021, April 20). Local Food Directories: Agricultural Marketing Service. United States Department of Agriculture. Retrieved from https://www.ams.usda.gov/local-food-directories/farmersmarkets

Warsaw, P., Archambault, S., He, A., \& Miller, S. (2021). The economic, social, and environmental impacts of farmers markets: Recent evidence from the us. Sustainability, 13(6), 3423. 